\title{
Evolution of the Brazilian Electric Generation System and Its Exergetic Efficiency-Relations with Economics, Reviews \& Projections
}

\author{
Marcus Vinicius da Silva Neves \\ exergetica.com.br, Rio de Janeiro, Brazil \\ Email: exergetica@exergetica.com.br
}

How to cite this paper: da Silva Neves, M.V. (2018) Evolution of the Brazilian Electric Generation System and Its Exergetic Efficiency-Relations with Economics, Reviews \& Projections. Open Access Library Journal, 5: e4135.

https://doi.org/10.4236/oalib.1104135

Received: November 9, 2017

Accepted: January 27, 2018

Published: January 30, 2018

Copyright $\odot 2018$ by author and Open Access Library Inc.

This work is licensed under the Creative Commons Attribution International License (CC BY 4.0).

http://creativecommons.org/licenses/by/4.0/

\begin{abstract}
In general, historically, Brazil is a country that does not develop a robust master plan for various areas responsible for supporting its development. As for the themes: education, transport, logistics, tourism, among others, the national infrastructure, in which the generation of electricity is a main character, does not have a strong planning and is pursued firmly that its actions come true. In addition, there is no clear driver for the system to seek in order to become more sustainable, reducing the economic, environmental and social impacts from the conversion of the energy potential of natural resources (renewable or not) into energy for society. The capacity of electric power generation is strategic for any country; it drives its economy and consequently its economic growth and increases the quality of life of its population. However, a robust planning is required to optimize the economics of electricity generation facilities in order to always meet the demand, without any significant spare capacity. Additionally, it is necessary to balance and evaluate the options available, so as to have a generating capacity which fulfills in addition to economic benefits, greater energy efficiency and reduced environmental impact, in order to allow the model to be sustainable. Thus, this paper presents the history and projections of population growth, evolution of GDP (Gross Domestic Product) correlated with the consumption and generation of electricity, as well as performs a calculation of the exergetic efficiency of Brazil's generating capacity for the production of direct correlations with its economic ability and associated environmental impacts, including the likely projections, providing means for reflection on the possibilities of planning and drivers for the future as well.
\end{abstract}

\section{Subject Areas}

Electric Engineering 


\section{Keywords}

Exergetic Efficiency, Country's Electrical System Master Plan, Electric Generation System

\section{Population Growth, GDP Growth, Energy Consumption-Comparisons and Projections}

With advances in technology, medicine (both reactive as preventive) and the economy, population growth has become exponential in the last two hundred years. Currently, according to the Department of Economic and Social Affairs of the United Nations [1], the world population growth rate is $1.2 \%$ per year. Apparently, it is a small rate; however, it is more than doubling the population every 50 years.

The world population in 1950 was 2.5 billion people. In 2000, there were more than 6 billion humans on the planet.

In Brazil, the annual growth rate is around 1\%. In 1970, we had 90 million. Forty-five years later, we spent 200 million Brazilians (more than doubled in 45 years) (Figure 1).

Correlating the rate of increase of energy consumption directly to the rate of population growth would be an acceptable model; however, there are other aspects to be evaluated.

According to the Department of Economic and Social Affairs of the United Nations [1], the population growth in Brazil and in the world should not keep the same recent rate. Several factors are responsible for this and are represented in the following charts, which present specific information from Brazil.

Figure 2 shows the history and the evolution of population projections in Brazil by variant and by age group.

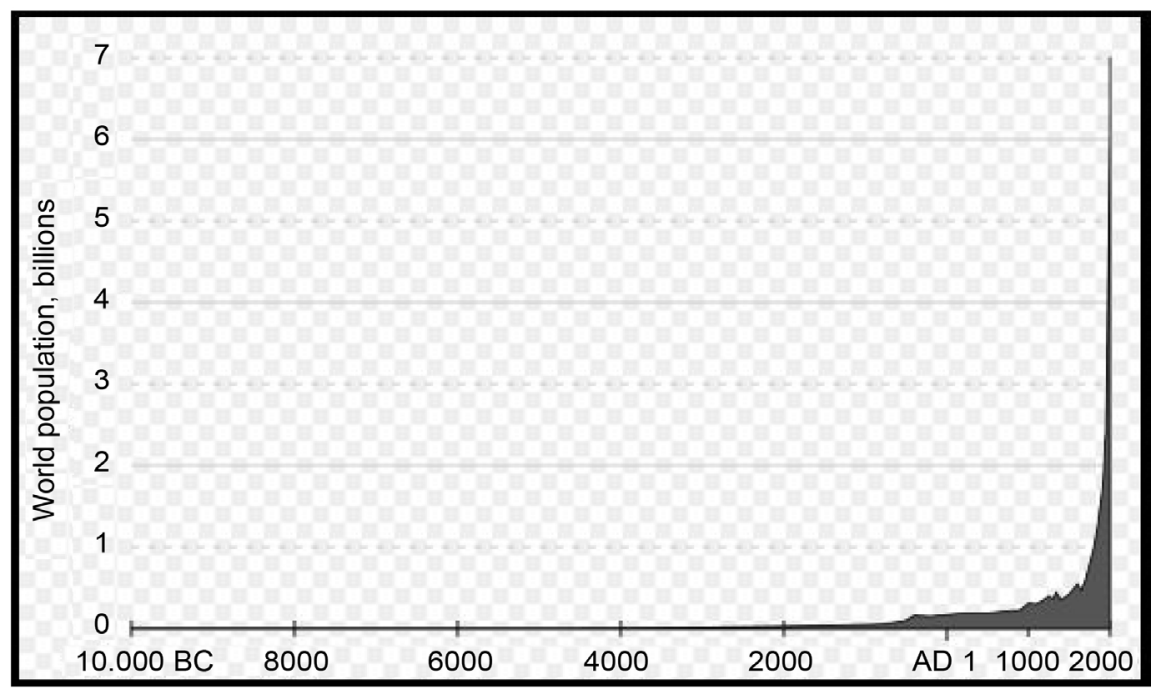

Figure 1. World population in history (amounts in billions). 
Figure 3 shows the history and the forecasts for fertility and infant mortality in Brazil.

And the Figure 4 presents the history and the forecasts for Life expectancy in Brazil and in Latin America.

By projections of population growth presented above, there may be a shift in the rising curve of the population by 2050 or earlier.

The main factor responsible for this change in behavior is the fertility rate of women that has been falling in Brazil since 1950 and will be stabilized just above
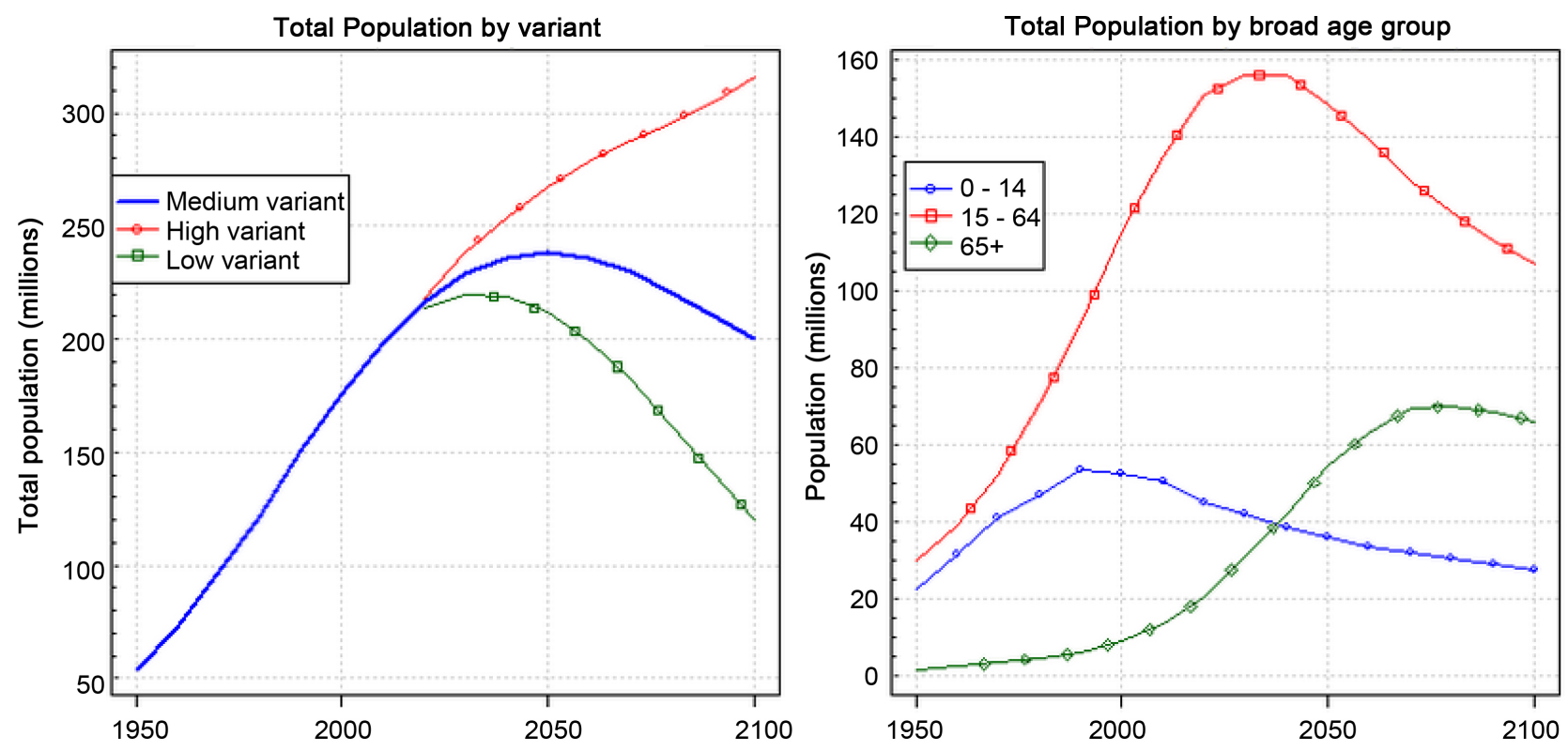

Figure 2. History and evolution population projections in Brazil.
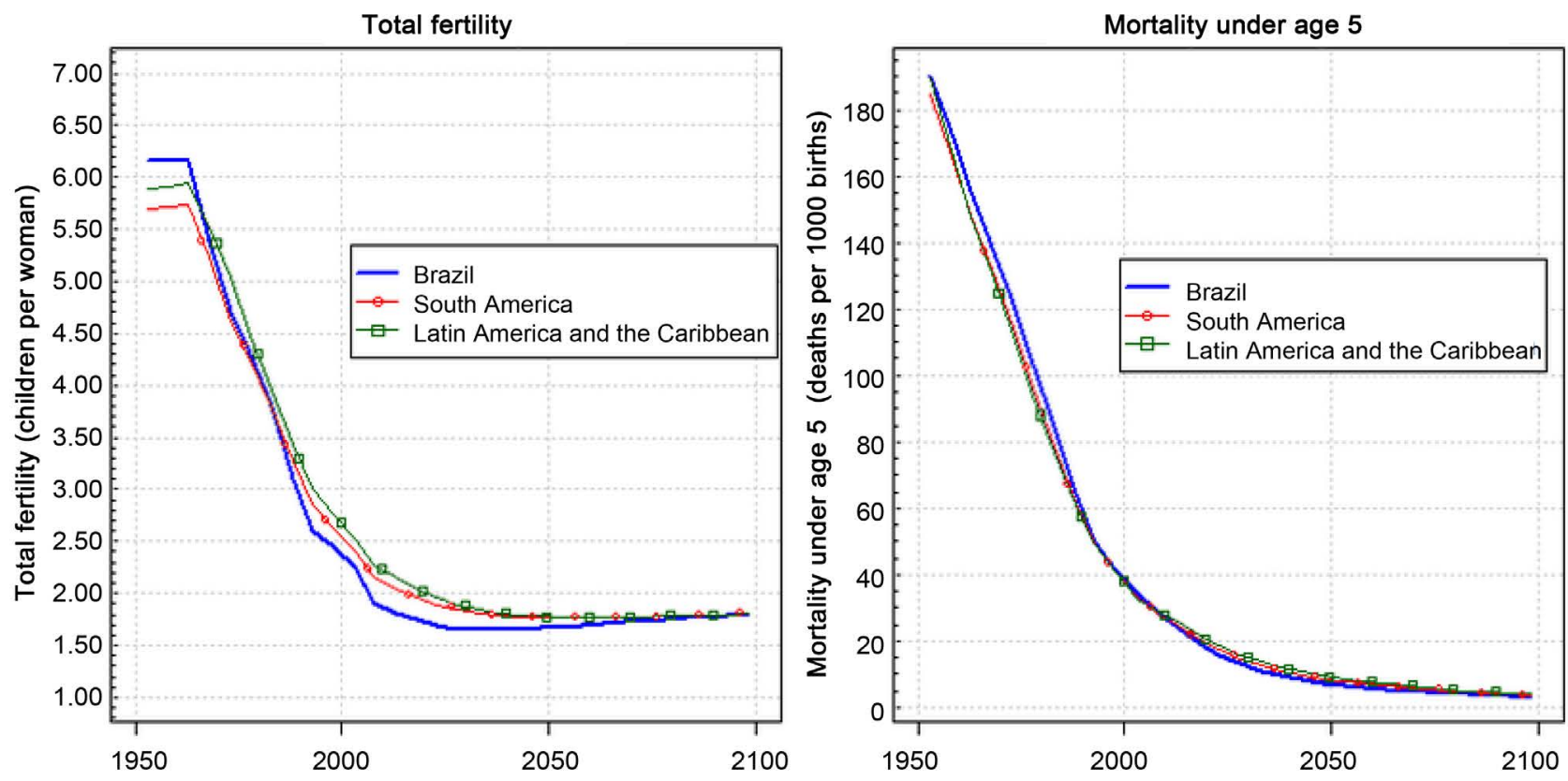

Figure 3. Fertility and infant mortality in Brazil and Latin America (historic and forecasts). 

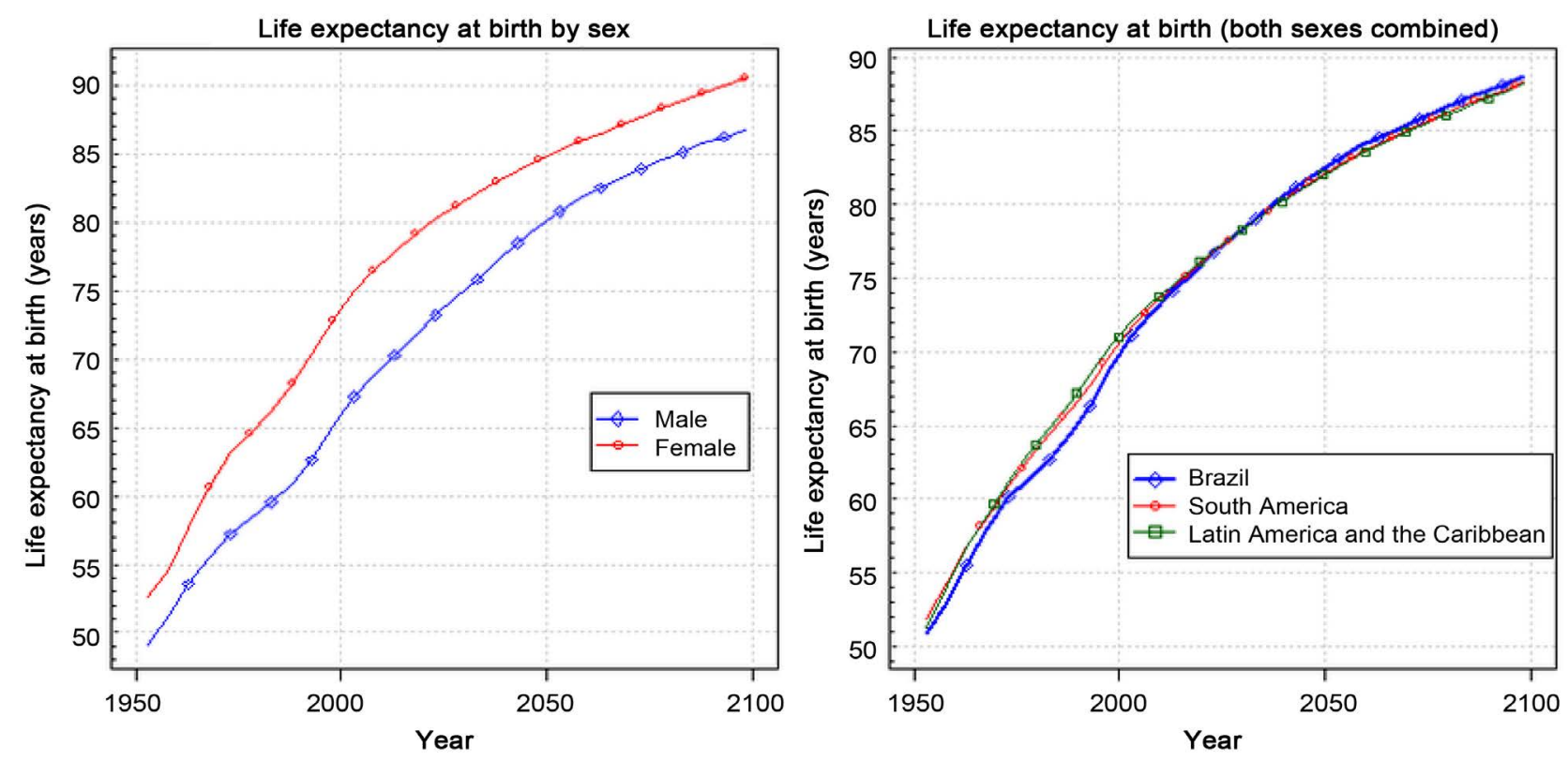

Figure 4. Life expectancy in Brazil and Latin America (historic and forecasts). Source: United Nations, Department of Economic and Social Affairs, Population Division (2015). World population prospects: The 2015 revision.

\section{5 children per woman from 2025 on.}

In any case, energy consumption is increasing alarmingly since the beginning of last century [2], as shown in the chart (Figure 5).

Apart from this, there is a huge discrepancy in relation to energy consumption per capita [3] between countries with different economic levels, as shown in the Figure 6.

United States, for example, consumes around 6 times more energy per capita than Brazil. Logically, this has full relationship with the level of industrialization and the weather of the country, but certainly also with the quality of life of the population.

Thus, the 30 developed countries that make up the Organization for Economic Cooperation and Development (OECD) are historically the world's largest energy consumers ${ }^{1}$.

Their share in total world, however, has retroceded over time. In developing countries, the relative share, although in some cases is not significant, as in Latin America, recorded a cumulative increase of more than $100 \%$ over the past three decades. This growth is related to economic growth in these countries, which allows gradual increases in the population's quality of life.

Hence, as previously presented, population growth alone already would require more and more energy; nevertheless, besides the increase in population, there is the constant increase in energy consumption per capita, in order to provide the level of quality of life consistent with the new economic levels systemat${ }^{1}$ OECD countries listed by the IEA are: Australia, Austria, Belgium, Canada, Czech Republic, Denmark, Finland, France, Germany, Greece, Hungary, Iceland, Ireland, Italy, Japan, Korea, Luxembourg, Mexico, Netherlands, New Zealand, Norway, Poland, Portugal, Slovak Republic, Spain, Sweden, Switzerland, Turkey, United Kingdom and United States. 
ically achieved.

Therefore, it is identified that there is an almost direct relationship between

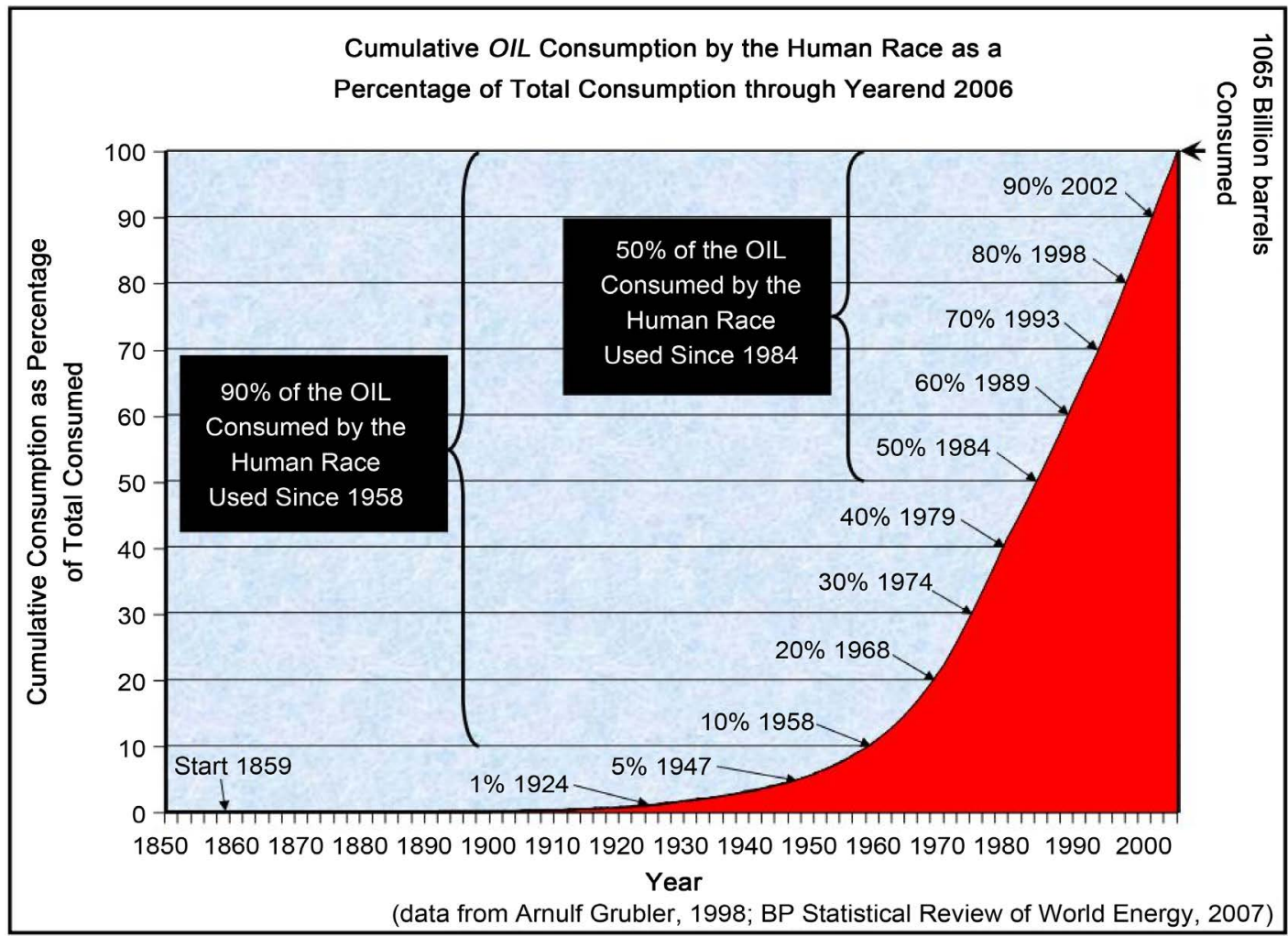

Figure 5. World oil consumption evolution.

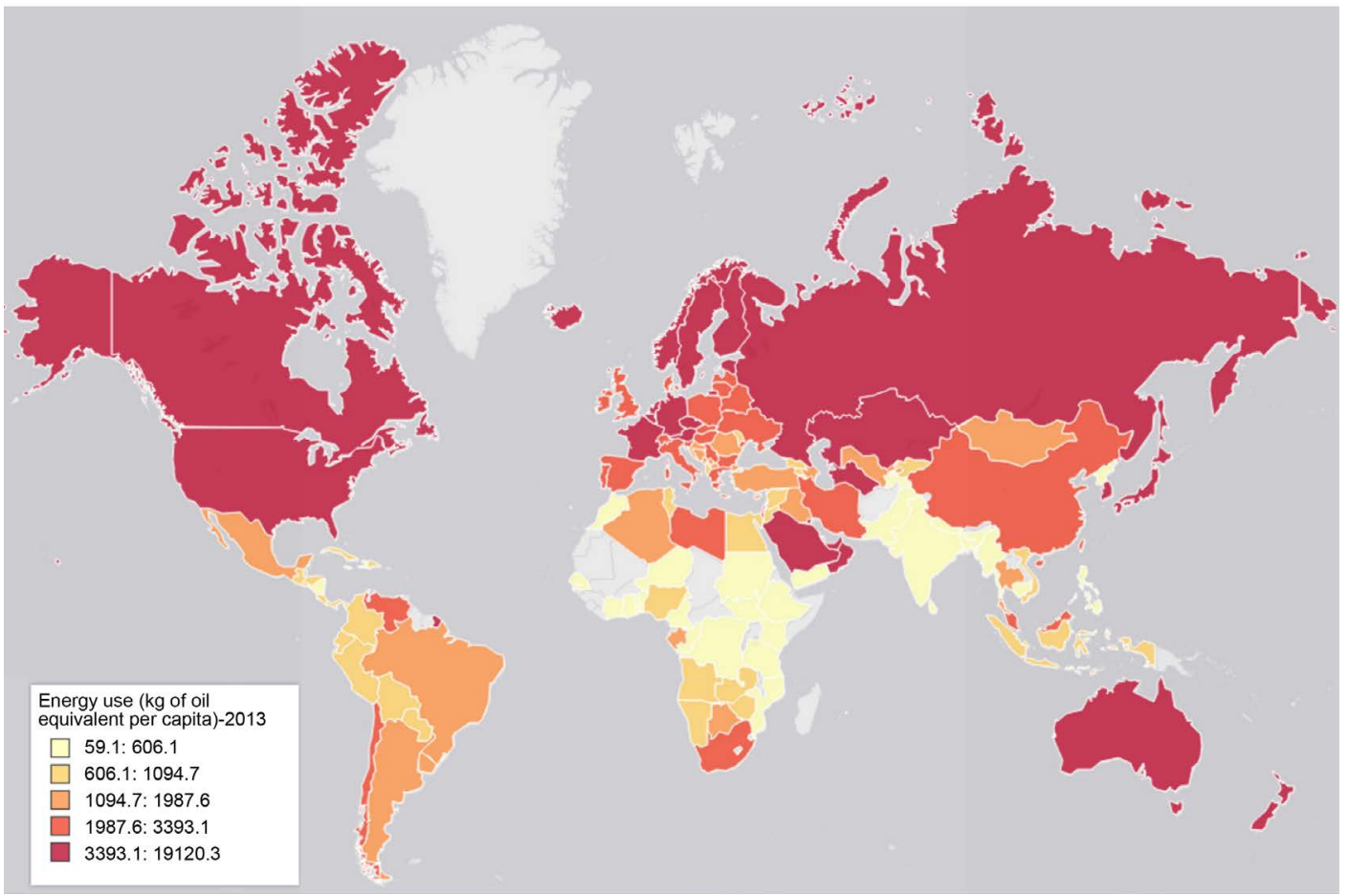

Figure 6. Energy consumption per capita in 2013 (in kg of oil equivalent). 
energy consumption of countries and people with their economic development level.

As a result, the GDP (Gross Domestic Product) in each country is directly related to its absolute energy consumption.

Returning to Brazil, the charts below (Figure 7 and Figure 8) show that GDP growth rates [4] and energy consumption [5] [6] [7] [8] [9] (in the graph represented by the electric power generation) are almost perfectly aligned.

Finally, after all this exposure, it is perfectly reasonable to project that in Brazil, population growth, energy consumption and economic activity represented by GDP are aspects that present total correlation and are associated basically following the same pace of evolution, at least for the next 20 or 30 years.

As a final reflection on this section, Stephen Hawking in his book "The Universe in a Nutshell" wrote: "In 2600, the world population will be packed shoulder to shoulder and the power consumption will cause the earth to shine a glowing red."

\section{History of Electric Generation in Brazil (2000-2016)}

Brazil is considered a privileged country in terms of energy resources and is taking advantage of its water potential for the generation of electricity. Until 2000, the hydroelectric plants accounted for over $95 \%$ of electricity generation in the

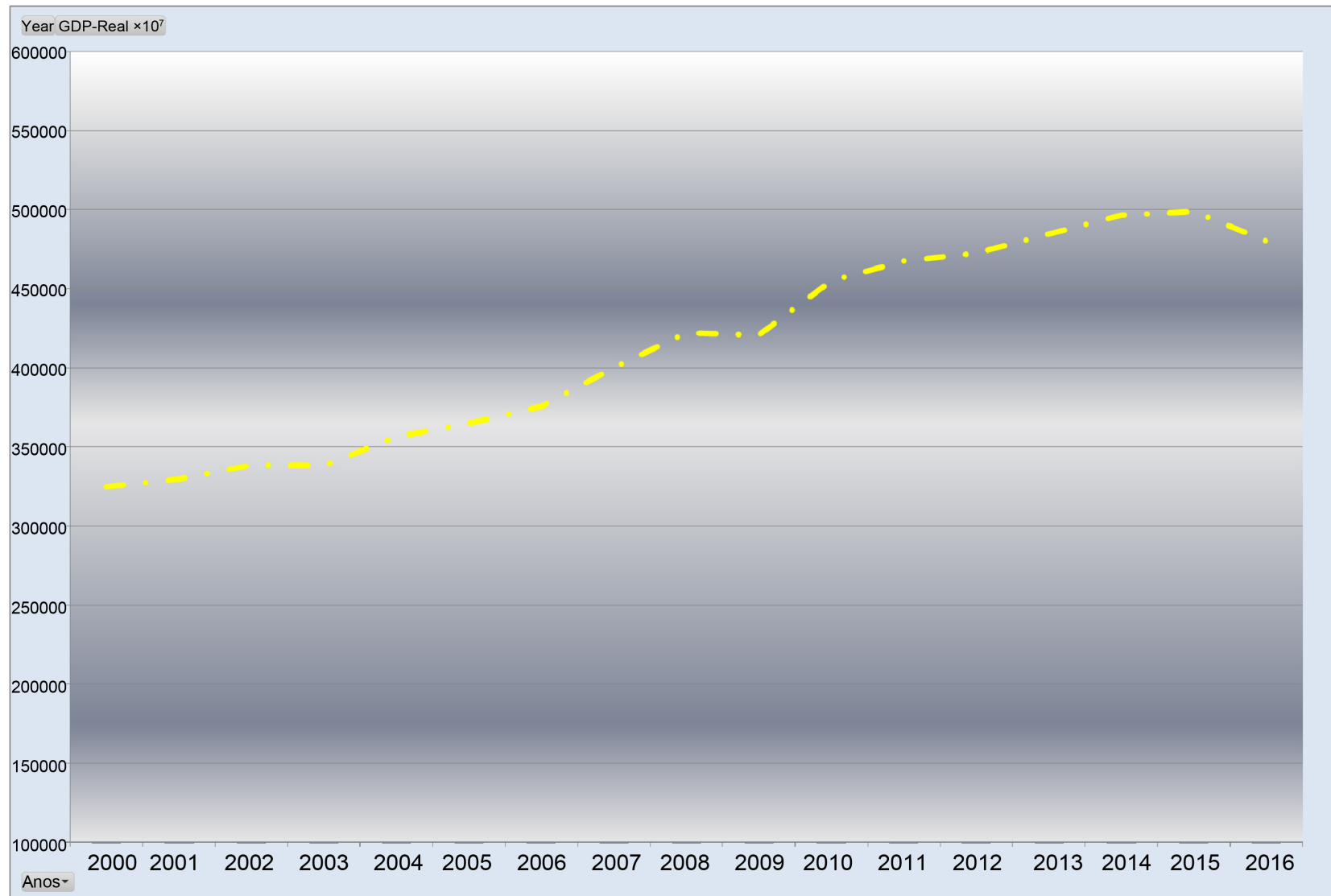

Figure 7. GDP growth in Brazil-2000-2016. 
country [5] [6] [7] [8] [9], as can be seen in the next figure (Figure 9).

In addition to the assessment of the proportion of each type of power generation in the Brazilian generation park, the above graph allows to perform various analyzes.

The first refers to the energy crisis in 2001, when demand tended to outstrip supply of electricity and consumers have had to reduce their consumption to the national electric system not to collapse. It is noticed that the power generation only returned to the 2000 level from 2003 on and not by chance, returning to Figure 7 and Figure 8, it is identified a stagnation of GDP between the years 2000 and 2003.

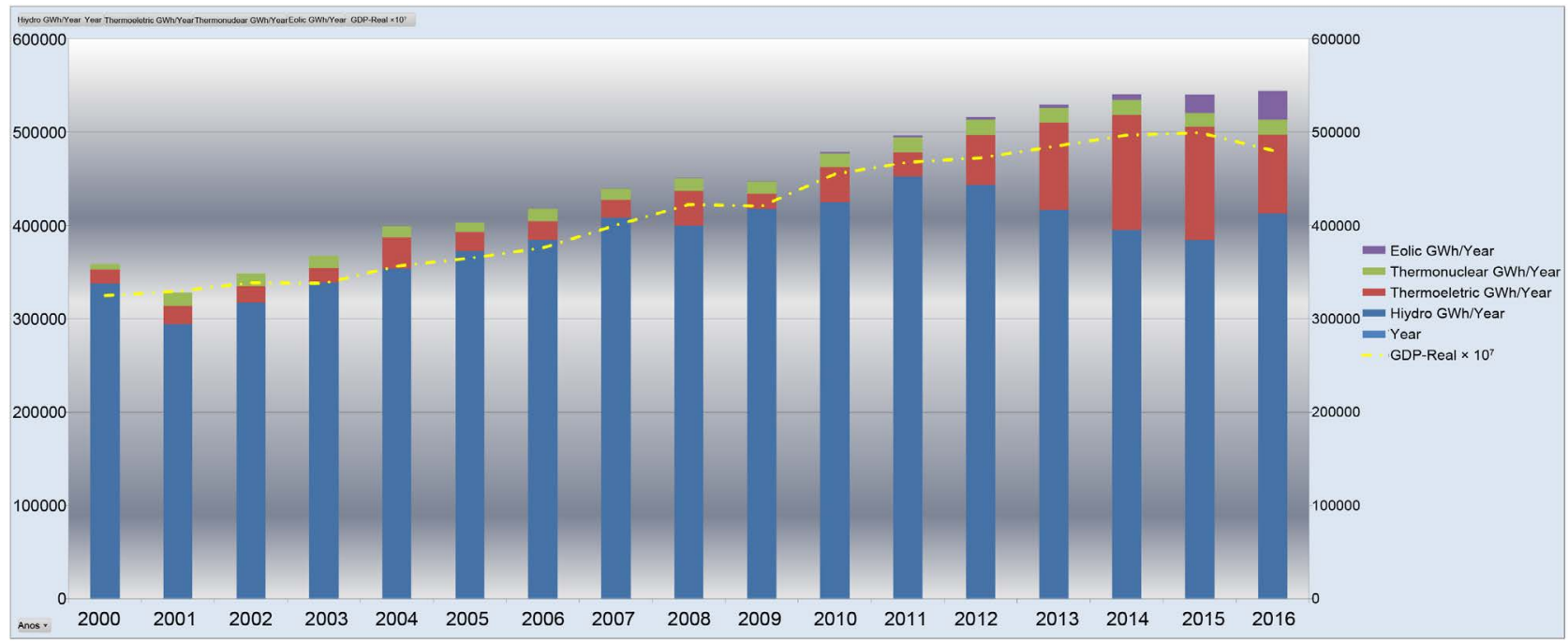

Figure 8. Power generation in Brazil $\times$ GDP growth-2000-2016.

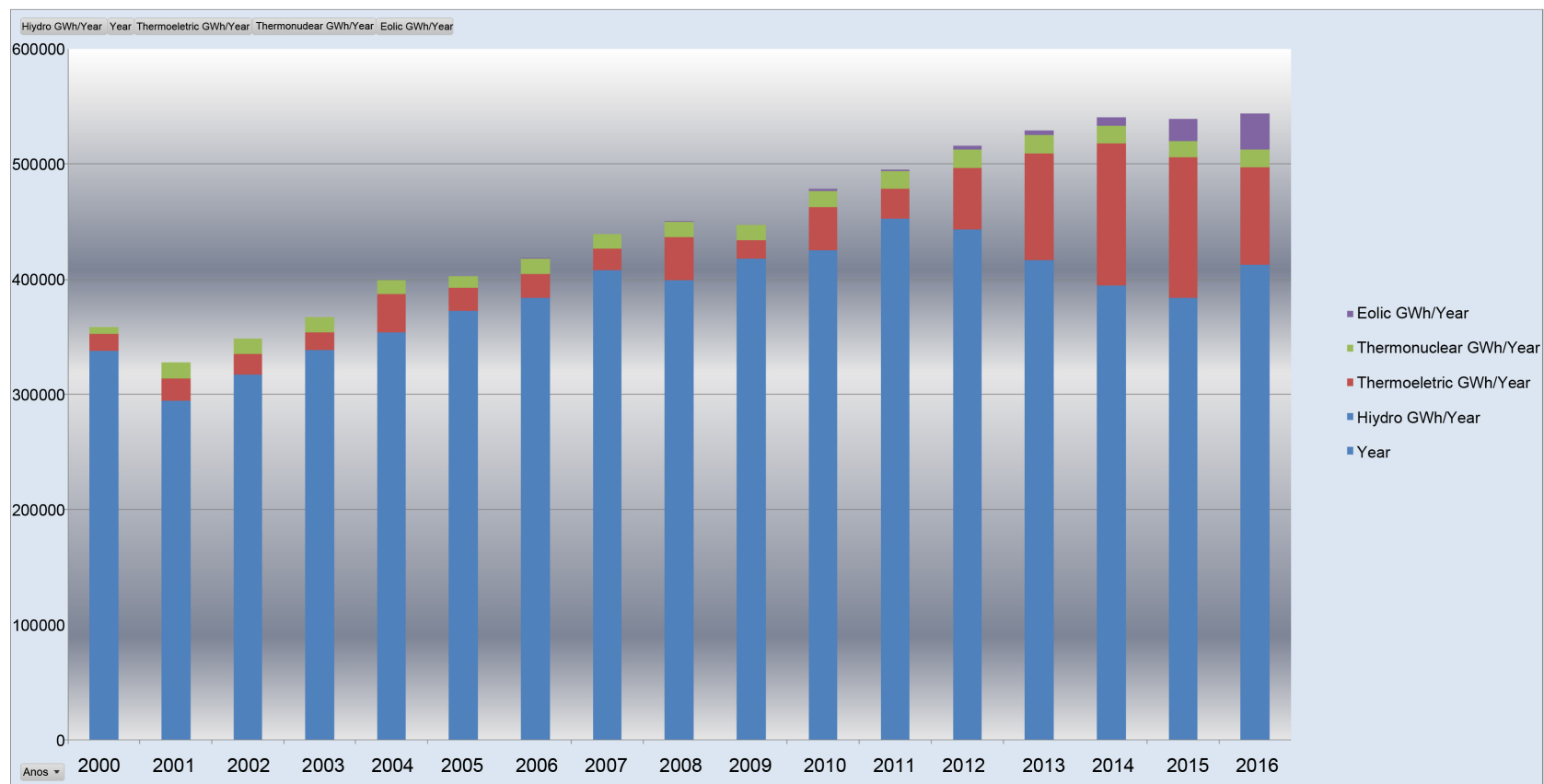

Figure 9. Power generation in Brazil-2000-2016. 
In addition, it is observed that, from 2001, there was an increase in the proportion of power generation by thermal power plants (conventional or nuclear), as an effort to use the existing park at that time in order to keep the generation level compatible with the required use.

Because of this crisis, there was an investment in increasing the national thermal power stations to enable the future regulation of levels of hydroelectric plant reservoirs. Hydroelectric power plants operate in the base system and conventional thermoelectric plants come into operation at peak times or where the average water levels of the reservoirs were threatened.

Already the wind modal began appearing in Brazil timidly only in 2006 and gradually increases in the minimum proportion of its participation in subsequent years.

Following the analysis, it is important to add more information to the chart. Thus, the next figure (Figure 10) adds the average level of water in the reservoirs of Brazilian hydroelectric plants [5] (chart orange line).

Returning to 2000, it appears that the average water level of the reservoirs was already low, falling further in 2001, providing the Brazilian electrical crisis. Basically, the country was many years without making investments to expand its hydroelectric park and even investment in creating a thermoelectric park was very shy. Added to this, smaller amounts of rain, it was not possible to prevent the crisis in Brazil.

Fortunately, even without capitalize on investments in the increase of the electricity generation system; the reservoir water levels rose again from 2002 onwards, freeing Brazil from offer $\times$ electricity demand crisis.

With the increase in reservoir levels and the gradual development of the

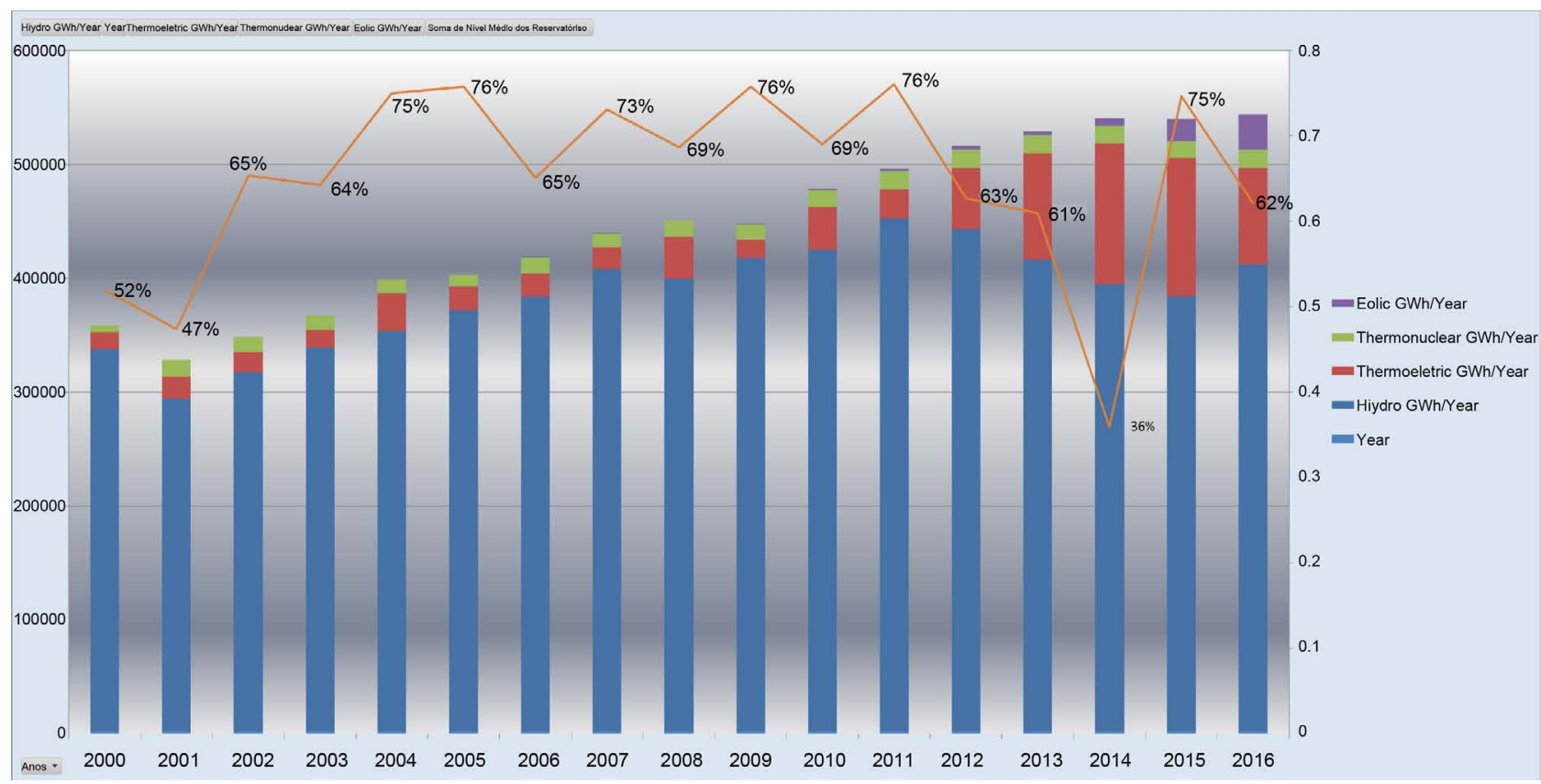

Figure 10. Power generation in Brazil $\times$ Middle level evolution of water reservoirs-2000-2016. 
thermal generation park, the country's economy returned to grow in the period between 2004 and 2008, enabling the supply of the national electric system kept pace with increasing demand without major limitations.

Between 2008 and 2009, the global economic crisis caused, among other aspects, by the housing bubble in the United States, also affected the Brazilian economy and it is verified by Figure 8, an economic and electricity generation stagnation.

After the economic crisis (at least temporarily), economic growth returned, requiring more energy from the national system between 2010 and 2013. However, it is clear that in 2012, the thermal park (now more robust) had been used to regularize the average water level of the hydroelectric reservoirs that still fell again. Again due to the reduced rainfall. It is important to note that, although from 2010 the power generation of the total system has been growing over the years, the portion generated only by hydropower in 2012 was lower than in 2011, in 2013 was in the order of magnitude of 2009, in 2014 it was consistent with the hydropower of 2008 and in 2015 was comparable to the level of 2006. That is, there was a huge effort to maintain the water levels of the reservoirs and the customer service market, through increased use of thermal plants at the base of the electrical system. But mostly, as in 2000 and 2001, there was time to anticipate the situation that was also experienced in 2015 and possibly will happen in the coming years, as well, until effectively the potential of existing park be expanded, especially with the new hydroelectric plants under construction.

\section{Basics of Exergy}

Before the exergetic analysis method allows an intelligent and effective integration with the economic assessment resulting from this combination to exergoeconomics, as well as for integration with environmental issues, exergoenvironmental analysis.

Thus, the use of exergetic efficiency as a comparative manner between power generation methods and as a means of evaluating trends to assess the best and worst use of existing supplies, promotes a more direct and comprehensive manner through only one indicator, to assess, in addition to the potential energy consumption of the available natural resources, the economic viability of each solution and simultaneously the environmental impacts.

Consequently, in the course of this section, the basics of Exergy and Exergy analysis will be presented.

1) Exergy concept:

The exergy of a system in a defined state is the theoretical maximum useful work that can be obtained when it interacts with the environment from the state specified by the mutual thermodynamic equilibrium. The exergy is also known by the terms "availability" or "available energy" and, by its definition, its unit is the same of work or energy.

The energy is always conserved, and it can be stored and transferred. The 
exergy can also be stored and transferred. However, in general it is not conserved and can be destroyed.

The first law of thermodynamics establishes energy conservation, and does not distinguish between its various qualities, presenting a purely quantitative analysis. It is through understanding of the Second Law of Thermodynamics which presents the concept of entropy and its generation, that becomes possible to observe the difference between the quality of the processes. Entropy generation is directly related to the destruction of exergy. For this reason, some types of energy conversion, though with the same magnitudes have different potentials useful use. By combining these two laws of thermodynamics, the exergy gives us a right evaluation, because allows us to observe quantitative and qualitative aspects of the transformations occurred in the processes [10].

2) Etymology:

The word exergy derives from the Greek from the combination of the prefix ex-with the meaning of "external", "out", with ergon segment, with the meaning of "force" or "work": force out, or force that can be extracted.

The exergy has energy unit (or work).

The exergy, not energy, has economic value.

3) Characteristics of exergy:

The Exergy is a quantitative measure of system state deviation from the state of the environment. In a spontaneous process from the state of the system to the equilibrium with the environment, no useful work is done (minimum zero). For a system already in balance with the environment, exergy assumes its zero minimum value.

The exergy is an attribute of the combination of the system with the environment. Environment explicitly set (or implied). Exergy is a property.

The exergy can be stored, destroyed, and therefore generally is not conserved, and can be transferred between systems.

4) Exergetic analysis:

The Exergy analysis of a thermodynamic system is the identification and quantification of the irreversibility of the system based on input exergy (inputs) and output (products and waste) of its components. It allows to evaluate the deviation of the system and its components present in relation to the optimum performance. The Exergy analysis enables also the allocation of costs to the various currents correlating exergy to fuel costs and equipment.

5) Analysis method:

The most common form of thermodynamic analysis of a system is through the first law of thermodynamics, which postulates the principle of conservation of energy, however, this approach is only quantitative, with no distinction between the different qualities of energy conversion methods.

In consequence, there is the need to evaluate the second law of thermodynamics to identify the qualities of the processes through entropy concepts and its generation presented by this postulate. 
If the second law evaluates the generation of entropy, also identifies the destruction of exergy, and consequently an efficiency analysis based on the second law allows to determine the capacity to produce work from the process effluents, enabling a comparison with the capacity of the affluents.

That is, the final exergy can be compared to the initial exergy in any process. This is the basic principle of Exergy analysis that will be detailed in the next section.

The concept of actual efficiency is used to combine the two laws, through the calculated efficiency for each one [11]. The maximum efficiency of the first law quantifies the efficiency obtained by the maximum useful work $\left(L_{e x}\right)$ converted by an ideal reversible process from a source of energy $(Q)$.

$$
\eta_{I}=\frac{L_{e x}}{Q}
$$

The efficiency of the second law measures the deviation between the actual work obtained $(L)$ for the evaluated process and the maximum that would be obtained if the same process was ideal and reversible $\left(L_{e x}\right)[11]$.

$$
\eta_{I I}=\frac{L}{L_{e x}}
$$

The actual efficiency is the combination of these two efficiencies. It simultaneously measures the amount and quality of useful energy obtained by quantifying the maximum work in an ideal process discounted by the actual losses due to irreversibility of the process and the consequent generation of entropy [11].

$$
\eta_{\text {Real }}=\eta_{I} \cdot \eta_{I I}
$$

Thus, solving the Equation (3) using the Equations (1) and (2), one arrives at the expression of real effectiveness:

$$
\eta_{\text {Real }}=\frac{L}{Q}
$$

Equation (4) cannot be held still as an exergetic efficiency basis, as it evaluates the available exergy in the product, the actual work $(L)$, but does not identify the exergy of the fuel, that is provided with the heat $(Q)$.

Hence, for obtaining the exergetic efficiency, the use of the exergy of the fuel would be required, which in this case is the one that accompany the heat $Q$ and is defined according to the equation:

$$
E_{Q}=\left(1-\frac{T_{u}}{T}\right) \cdot Q
$$

Accordingly, the first definition for Exergy efficiency is given by the ratio between the exergy of the product $\left(E_{P}\right.$ in this case, $L$ ) and fuel ( $E_{O}$ assessed the situation, $E_{Q}$ ), according to the equation:

$$
\varepsilon=\frac{E_{P}}{E_{C}}=\frac{L}{E_{Q}}=\frac{L}{1-\frac{T_{u}}{T} \cdot Q}
$$


A comparison of efficiencies is the case of the electric shower, by the first law, its efficiency is high (near 100\%), since nearly all power is transformed into heat, which can be observed by the increasing water temperature; however, this hot water is not able to perform the same work as the power that heated it, i.e., the process is quite irreversible. Energy is conserved, but its quality has deteriorated, so the exergy decreased. It is not possible, using hot water, to generate the same electrical power that heated it and this is handled by the second law of thermodynamics. In practice, the exergetic efficiency of the electric shower is approximately zero.

In a plant composed by several processes and systems, the exergetic method enables not only the overall efficiency of the plant, but also the contribution of each portion to the degradation over the entire process from its initial exergy.

Therefore, one can determine which process in an installation is the most detrimental to its efficiency, or even to identify the contribution of the variation of a process's performance in the plant efficiency.

6) Thermal plants (Thermoelectric and thermonuclear):

In the case of thermal power plants (thermoelectric and thermonuclear), the exergetic efficiency is given by Equation (6), reproduced below:

$$
\varepsilon=\frac{L}{1-\frac{T_{u}}{T} \cdot Q}
$$

Figure 11 identifies the theoretical limits of Exergy efficiency for thermal energy conversion.

Moreover, it shows the growth of exergetic efficiency, from zero to the asymptotic approximation to the reference. The zero efficiency occurs in a system that allows the primary source of equilibrium with the environment without any useful benefit. As the system takes advantage from the fuel exergy in a useful

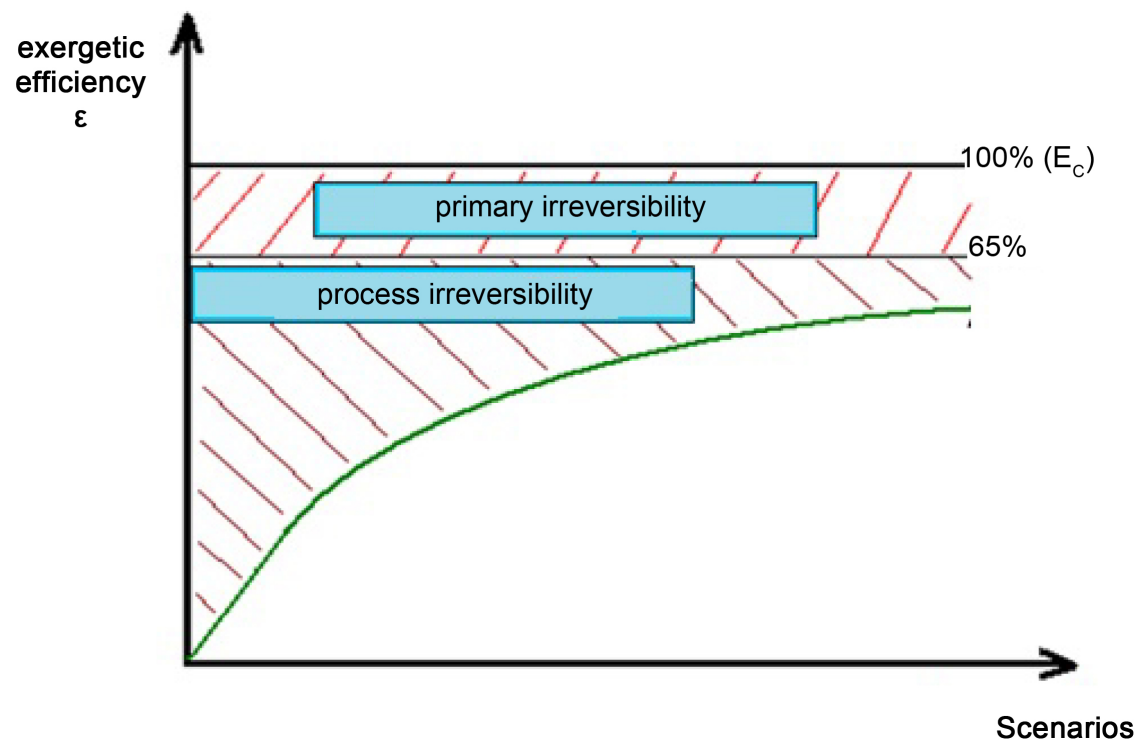

Figure 11. Limits of energy efficiency in thermal generation. 
way, the exergetic efficiency increases toward the value of the theoretical reference to a maximum level determined according to the irreversibilities level of these processes, the type of primary power generation (single or open cycle, combined cycle) and the existence of thermal demand for cogeneration in the installation. In other words, the unit will never reach the maximum theoretical reference, because not only the primary conversion is irreversible (primary irreversibility), but there are other processes, which are also irreversible and therefore they also destroy exergy (process irreversibility). The asymptotic behavior of the curve shown in the figure occurs due to the existence, in addition to the primary energy conversion, of one or more actual processes that convert energy, as well.

For this article, it was used conservatively, the exergetic efficiency of $60 \%$ for combined cycle (40\% of the Brazilian total thermal generation) and $30 \%$ for simple open cycle ( $60 \%$ of the Brazilian total thermal generation).

For thermonuclear plants (all in simple open cycle), we used the exergetic efficiency value of $30 \%$.

7) Hydraulic and Eolic plants:

Equation (7) below refers to the theoretical definition of exergetic efficiency for the hydraulic and wind power plants (disregarding the variations of kinetic and potential energy).

$$
\varepsilon=\frac{L}{\left(H_{1}-H_{2}\right)-T_{0}\left(S_{1}-S_{2}\right)}
$$

The difference compared to the previous example is to calculate the exergy of the fuel, which in this case refers to the enthalpic jump of the working fluid (water or air).

In this study, it was used the $60 \%$ value for the exergetic efficiency of hydraulic and wind power plants.

\section{History of Energy Efficiency in Brazil-Assessment of the Current Situation, Trends and Projections}

Despite the great concern in Brazil is related to meeting the energy demands of the country to provide its economic growth and even to maintain, minimally, the current levels of consumption at the current baseline, the energy efficiency cannot be forgotten because the consumption of natural resources, renewable or not, cannot be unlimited. And especially, the country needs to define a master plan for its future generating facilities, which naturally needs to be economical, but definitely needs to be sustainable.

As a result, nothing better than the assessment of Exergy efficiency, because it can be directly correlated to economic viability of the solutions through exergoeconomic analysis, as well as the environmental impact assessments by means of exergoenvironmental studies.

Thus, the exergetic inefficiencies can be correlated to the inexorable destruction of the inputs (resources), reversing in economic losses, and environmental 
degradation, as the energy waste (physical or chemical), arising from the inefficiencies of energy conversion processes, need to be again brought to the equilibrium condition with the environment, causing an environmental cost.

The following Figure 12 sum the historical Exergy efficiency line (blue line) to the information provided earlier in this article.

It can be seen clearly a downward trend in exergetic efficiency due to the gradual increase in the use of thermal power plants (mainly in an open cycle), since the share of conventional thermal power plants in the annual amount of energy generated came from little over $4 \%$ in 2000 to almost $16 \%$ in 2016.

This trend of Exergy efficiency drop of the national electric generation park follows the reverse path than would be appropriate to move towards sustainability.

The next Figure 13, in addition to the historical values of exergetic efficiency (yellow line), the trend line (red dashed line) reaching a Exergy efficiency value bellow 50\% in 2030 (considering that this future projection follows the same current trend) and a sustainable projection (orange dashed line) with the increased use of wind and hydro power, and use of thermal plants in combined cycle, reaching the technologically optimum level of $60 \%$ of exergetic efficiency in 2030.

It is important to note that the difference between the value of $60 \%$ of Exergy efficiency of sustainable projection and 50\% to the current trend for 2030 may seem small, but it creates the need for more $10 \%$ in natural resources (fuels), which are reversed in more economic expenditures. And 10\% of exergy inefficiency represents more effluents in disequilibrium with the environment that will generate greater environmental costs to bring them to physical and chemical equilibrium with its surroundings.

These differences added up over the years represent a fortune on consumption

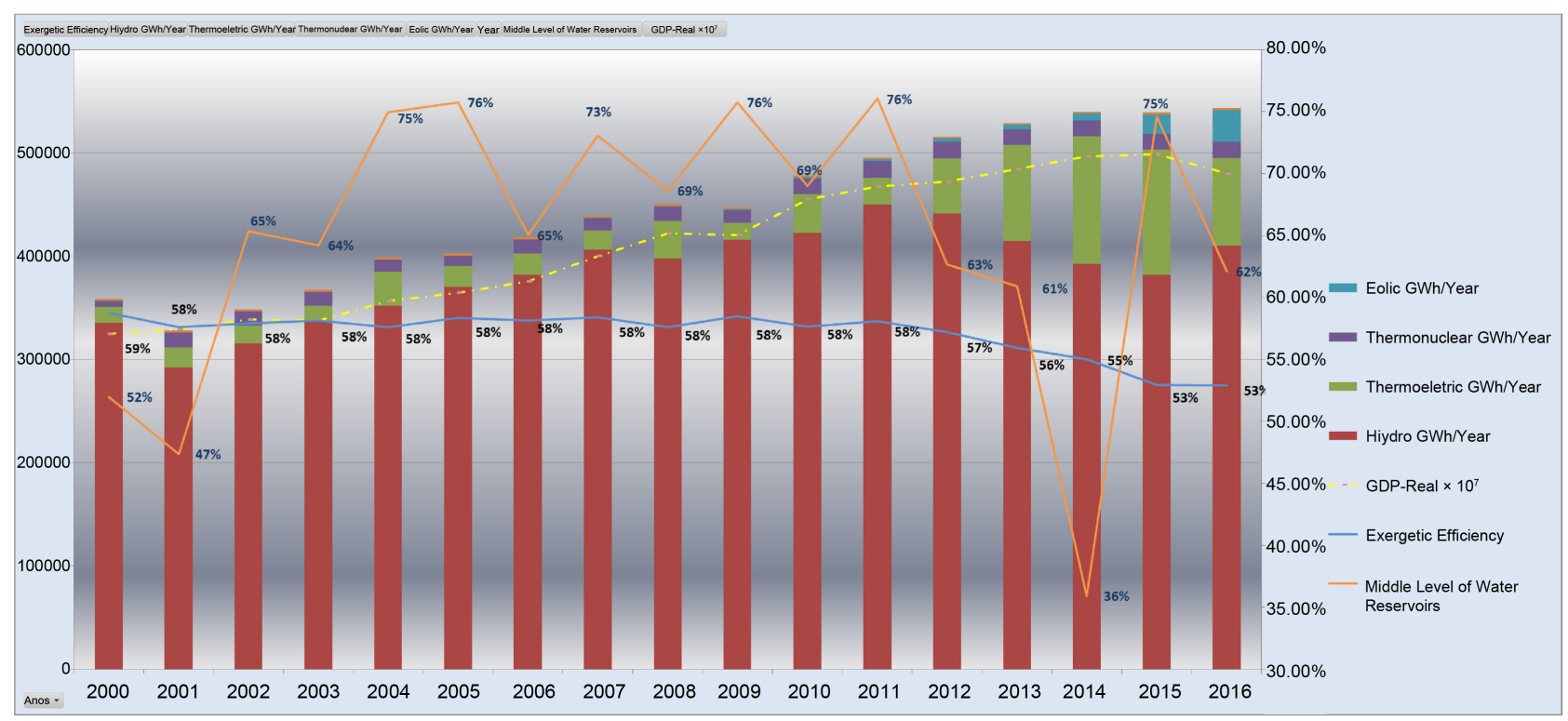

Figure 12. Exergetic efficiency of power generation in Brazil $\times$ Middle level evolution of water reservoirs and GDP-2000-2016. 


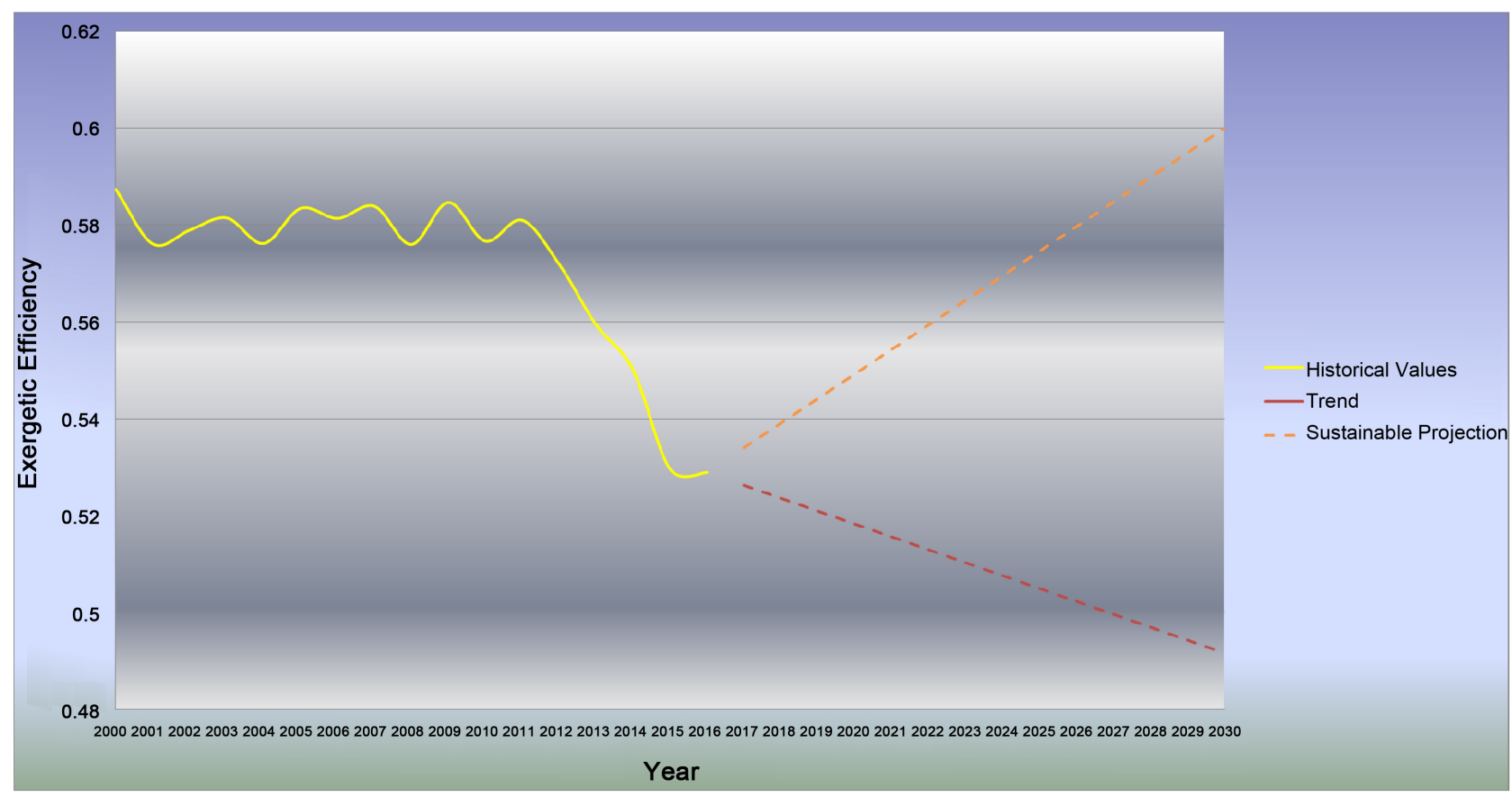

Figure 13. Exergetic efficiency-history and projections.

of resources and environmental impacts that may become increasingly worrying.

\section{Conclusions}

The main conclusions derived from the series of information and analyses presented are:

- The evolution of energy consumption in Brazil and in the world has direct correlation with population growth and GDP, both as absolute and per capita, as well as with the improvement of people's quality of life.

- Thus, it is perfectly reasonable to project that in Brazil, population growth, energy consumption and economic activity represented by GDP will be associated basically following the same pace of development, at least for the next 20 or 30 years.

- For at least twice (next to 2000 and from 2012), the national electrical system gave anticipated signs that would collapse, but the country was not adequately prepared to deal with energy planning to address the implementation of an acceptable electric infrastructure with strong correlation with the country's economic growth. Rely on its electric generation structural plan to almost exclusively the random occurrence of a higher volume of rain in order to avoid the energy supply crises.

- Because of the 2001 crisis, there was an increased investment in expansion of the thermoelectric generation park, especially with conventional thermoelectric plants in an open cycle. Such plants should not be used in the base of the national electric generation system, but only to meet peak demands. However, more recently, between 2010 and 2012, they began to be used more intensively in the base of the electrical system (and continued to be used in subse- 
quent years) to preserve the water levels in the hydroelectric plant reservoirs, due to the lower volume of rains during that time and little investment in new hydric power plants, in addition to the very low use of unconventional electric generation alternatives such as wind and solar.

- As a result, the exergetic efficiency of the national power generation system is gradually decreasing (from close to $60 \%$ in the year 2000 to around $53 \%$ in 2016) and the trend is that its value reaches a level below $50 \%$ in 2030. This involution is totally against the sustainable development and will cause a big environmental impact in the future, and therefore will have a non-calculated negative contribution to the global warming process.

- The difference between the $60 \%$ exergetic efficiency of sustainable projection and 50\% for the current trend towards 2030 (that were presented in the Figure 13) may seem small, but it generates the need for a further $10 \%$ in natural resources, which are reverted in more financial expenditures. And more $10 \%$ of exergetic inefficiency represents more effluents in disequilibrium with the environment that will generate a greater environmental cost to bring them to the physical and chemical balance with their surroundings.

- As options to promote the gradual increase in exergetic efficiency of the national electricity system, the use of unconventional electric generation alternatives in Brazil, but common in other countries, such as wind and solar ones, should be contemplated in the Brazilian energy matrix. These actions will also increase the percentage of renewable energy use in the generating park, moving towards sustainability and reducing the environmental impacts. Additionally, the thermoelectric plants in open cycle shall close their thermodynamic cycles, in order to reach the highest level that is feasible in this type of technology.

- Several alternatives exist to increase exergetic efficiency with low costs; however, the actions must be structured and planned. Some countries, such as Germany, promote tax incentives for individuals who install energy generation systems (whether for heating or photovoltaic) in their homes for their own consumption, with synchronization option with the public grid for surplus sales.

Finally, historically Brazil is a country that does not develop a robust master plan for various areas that are responsible for supporting its development. As for the themes: education, transportation, logistics, tourism, among others, the national infrastructure, which the generation of electricity is a main character, does not have a strong planning and tracked firmly that their actions come true. Furthermore, there is not a clear driver for the system to seek to become more sustainable, reducing the economic, environmental and social impacts from the conversion of the energy potential of natural resources (renewable or not) into energy for society.

\section{References}

[1] United Nations, Department of Economic and Social Affairs, Population Division 
(2015) World Population Prospects. The 2015 Revision.

[2] BP Global. http://bp.com

[3] World Bank. http://www.worldbank.org

[4] Institute of Applied Economic Research (IPEA). http://ipeadata.gov.br

[5] Brazilian National Electric System Operator (ONS). http://ons.org.br

[6] National Electric Energy Agency (Aneel). http://aneel.gov.br

[7] Energy Research Company (EPE). http://epe.gov.br

[8] International Energy Agency (IEA). http://iea.org

[9] Ministry of Mines and Energy (MME). http://mme.gov.br

[10] Bejan, A. (1988) Advanced Engineering Thermodynamics. John Wiley \& Sons, New York.

[11] Stephan, K. and Mayinger, F. (1998) Thermodynamik, Band 1: Einstoffsysteme. Grundlagen und technische Anwendungen. 15th Edition, Springer-Verlag, Berlin, Heidelberg, New York. 